\title{
Aortocaval fistula and bluish red color skin change
}

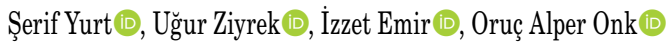 \\ Department of Cardiovascular Surgery, Erzincan Binali Ylldirm University Medical Faculty, Erzincan, Turkey
}

\begin{abstract}
Aortocaval fistula is primarily arisen from necrotic aortic tissue with disrupted connective tissue and adherent to adjacent venous structures mostly in abdominal aortic aneurysms. The endoleak which appeared after endovascular aneurysm repairs can also cause this presentation. Thrill is possible to be felt in abdominal examination in aortocaval fistulas, and skin changes suggestive of venous hypertension usually occur in the body. Aortocaval fistula can cause high output cardiac failure, require an immediate intervention and endovascular methods are considered to be prior in its treatment. In this article, we present endovascular treatment of aortocaval fistula secondary to Type 3 endoleak.

Keywords: Arteriovenous fistula, endoleak, endovascular procedure.
\end{abstract}

Primary aortocaval fistula $(\mathrm{ACF})$ is a rare component of abdominal aortic aneurysm (AAA), accounting for less than $1 \%$ of all AAAs. It is encountered 2 to $6 \%$ more frequently in ruptured AAAs. ${ }^{[1]}$ The most common reasons for secondary ACF are penetrating abdominal injuries. A total of $80 \%$ of ACFs are caused by primary aneurysms, while $15 \%$ are secondary to trauma and $5 \%$ are iatrogenic (post-lumbar disc hernia surgery or late complication of endovascular aneurysmal repair [EVAR])..$^{[2]}$

Secondary necrosis and inflammation occur in all layers of the aorta with aneurysmal, thinning, connective dissue disruption and inflammation in the adventia layer affects the adjacent venous structures, thereby, leading to ACF due to necrotic adhesion. This has been the most accepted theory for the pathophysiology of ACF formation..$^{[3]} \mathrm{An} \mathrm{ACF}$ is rarely seen like aortoenteric fistulas, and death is inevitable, if left untreated. ${ }^{[4]}$

In this article, we present a case of ACF caused by Type- 3 endoleak, as one of the late complications of EVAR, and its treatment with endovascular method.

\section{CASE REPORT}

A 68-year-old male patient was admitted to the emergency department after a sudden onset of abdominal pain, fainting, and general condition disorder. The patient was confused, tachypneic, tachycardic (110 bpm) and hypotensive $(85 / 40 \mathrm{mmHg})$ at the first evaluation in the emergency department. There was a palpable pulsatile mass and widespread tenderness in the abdominal examination. Thrill was particularly felt on palpation in the left lower quadrant of the abdomen. There were bluish red ecchymotic bruises starting from the upper quadrant of the abdomen extending to the feet (Figure 1a, b). These skin changes were similar to those in phlegmasia cerulea dolens with a venous hypertension sign and started about $2 \mathrm{~h}$ before application. The distal pulse of the patient was weak. There was edema in the legs, and scrotal edema and priapism were also present. One year ago, the patient underwent EVAR due to an AAA $(80 \mathrm{~mm}$ in diameter and $10 \mathrm{~cm}$ in length at the infrarenal level). Intravenous contrast-enhanced abdominal computed tomography angiography

Received: December 28, 2020 Accepted: February 01, 2021 Published online: March 11, 2021

Correspondence: Şerif Yurt, MD. Erzincan Binalı Yıldırım Üniversitesi Tıp Fakültesi Kalp ve Damar Cerrahisi Anabilim Dalı, 24100 Erzincan, Türkiye. e-mail: yurt_serif@hotmail.com

Yurt Ș, Ziyrek U, Emir İ, Onk OA. Aortocaval fistula and bluish red color skin change. Turk J Vasc Surg 2021;30(3):241-244 

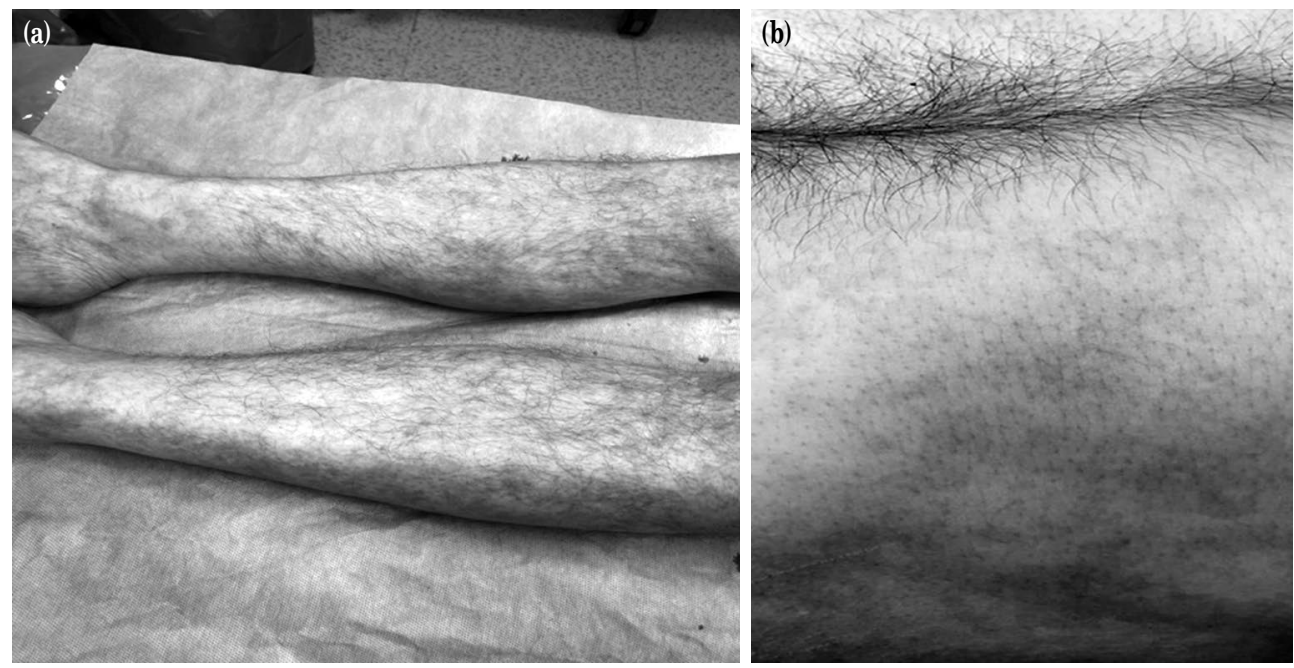

Figure 1. (a) Skin changes suggestive of venous hypertension. (b) Skin changes suggestive of venous hypertension

imaging revealed that the graft-covered stent placed in the left common iliac artery during the EVAR procedure was detached from the main body of EVAR and migrated to the distal. This space caused extravasation and an AAA formation up to $9 \mathrm{~cm}$. Contrast transition from aneurysm sac to the vena
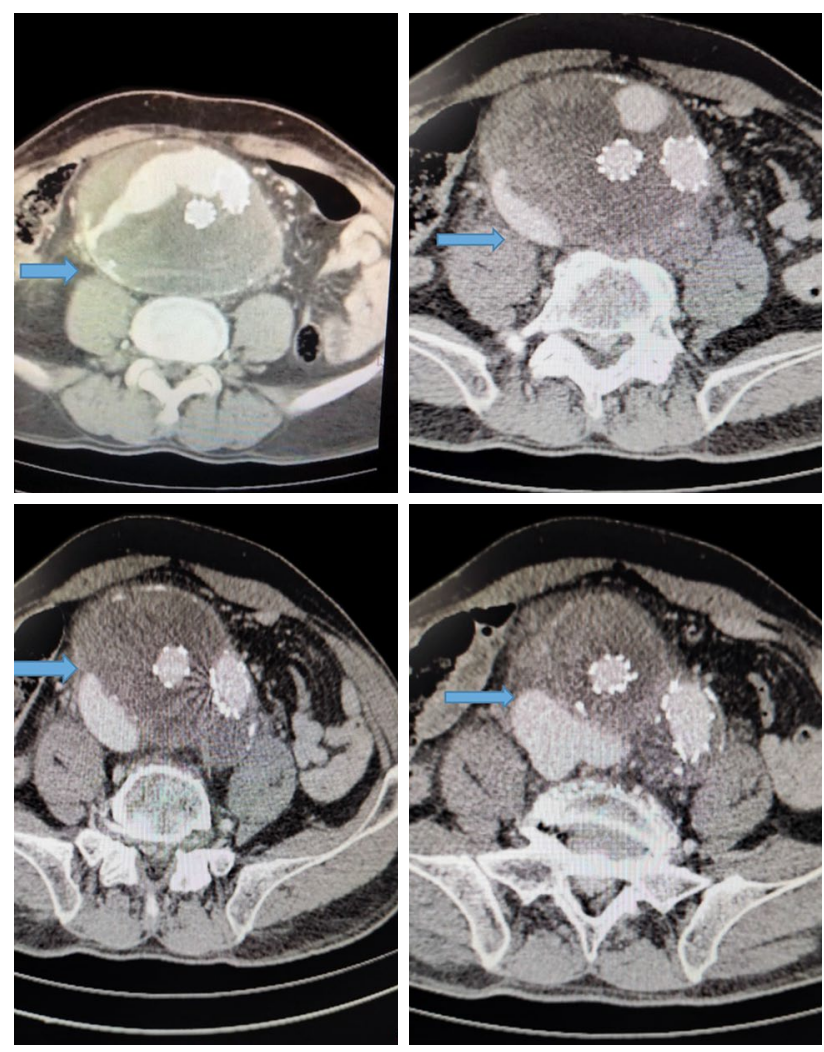

Figure 2. Type 3 endoleak and aortocaval fistula. cava inferior was noticed (Figure 2). Post-EVAR Type-3 endoleak and ACF were observed.

The patient was taken to the intensive care unit. High cardiac output was present on the cardiac failure presentation. There was no urination for $6 \mathrm{~h}$ during the surgical preparation. A written informed consent

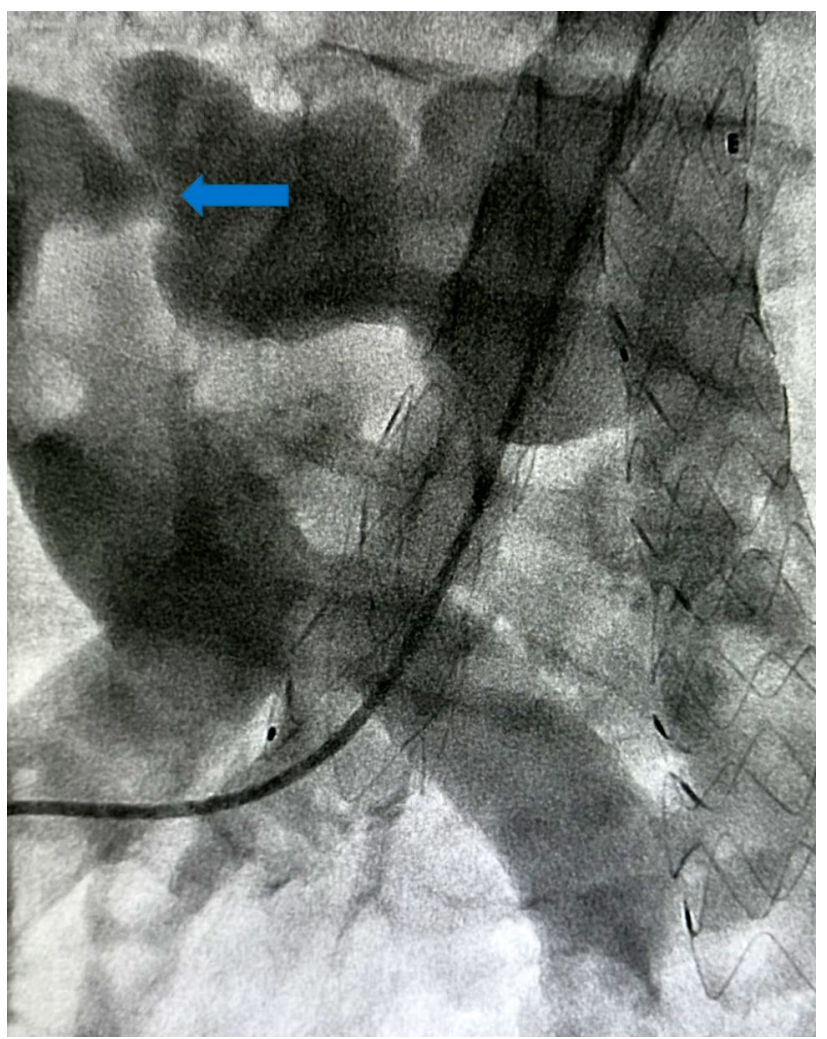

Figure 3. A conventional angiography image of aortocaval fistula. 


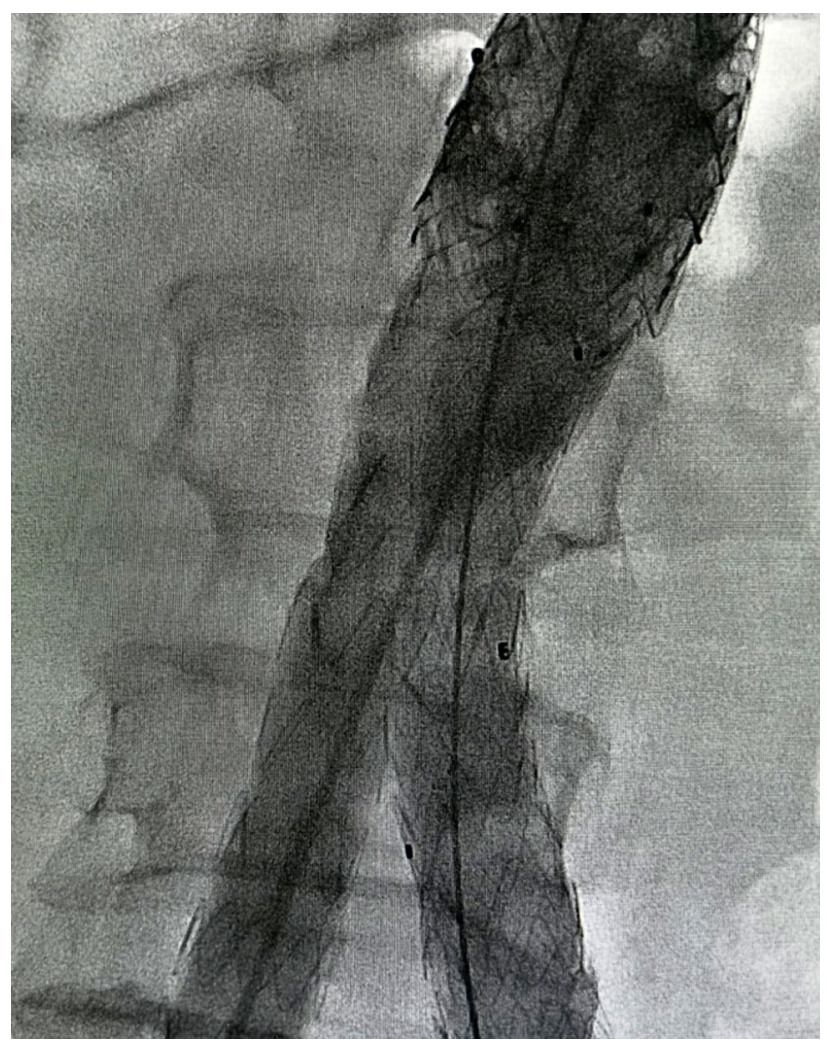

Figure 4. A conventional angiography image after closing the space causing endoleaks.

was obtained from the patient. In the operating room, after exploration of the femoral artery under spinal anesthesia, the patient was taken to the angiography unit. The patient was heparinized. With the Seldinger method, the femoral artery was accessed, a $5 \mathrm{~F}$ catheter was placed, a hydrophilic guidewire and pigtail catheter were sent, and imaging was performed. Type 3 endoleak and ACF were visualized (Figure 3 ). The endovascular diameter of $16 \mathrm{~mm}$ (proximal) $\times 24 \mathrm{~mm}($ distal $) \times$ $156 \mathrm{~mm}$ (length) covered graft stent (Endurant ${ }^{\mathrm{TM}}$; Medtronic Cardiovascular, CA, USA) was placed from inside the main body of the EVAR graft at the beginning of the left common iliac artery to the internal iliac separation into the migrating EVAR elongation graft in the distal. The thrill felt in the abdomen disappeared as the covered graft stent closed the defect which caused the aneurysm sac to fill. On imaging studies, there was no extravasation to the aneurysm sac, and ACF was closed (Figure 4). Immediately after the procedure, tachycardia of the patient regressed, tachypnea no longer existed, and sufficient urination began to occur. The patient who had no complications during follow-up was discharged three days later.

\section{DISCUSSION}

Endoleak is one of the most important complications of EVAR which continues flowing into the aneurysm sac after the graft covered stent is placed in the aneurysmatic aorta. ${ }^{[5]}$ Endoleaks have five types. Type 3 endoleak is caused by the separations of EVAR graft fragments. ${ }^{[6]}$

In the presented case, the flow induced by Type 3 endoleak occurred in the aneurysm sac, the aneurysm sac ruptured into the vena cava, and caused ACF. The ACFs are usually encountered in ruptured AAAs without a history of previous intervention. ${ }^{[1]}$ As a late complication after EVAR attempts, the endoleak causes ACF to rupture in the aneurysm sac as a rare condition. The current situation may be due to the continuation of enlargement in the existing aneurysm, as well as insufficient planning before surgery and inappropriate use of grafts for anatomy. Therefore, a detailed mapping of anatomical suitability before surgery can reduce such intervention-related complications.

The mortality rate of open surgical repairs in ACF treatment ranges from 12 to $25 \% .^{[7]}$ Particularly, if $\mathrm{ACF}$ is in a chronic phase, intraoperative major bleeding can be seen from the arterialized venous structures, therebyincreasing the mortality. In addition, complications increase in patients operated for AAA rupture without ACF noticed before surgery. Review of the literature reveals that if there is anatomical suitability to intervene in the cardiac decompensation process very quickly, endovascular methods are usually preferred in the treatment of ACF patients with highoutput cardiac failure.

In our case, the importance of taking medical history and uncommon physical examination findings is emphasized. Previous EVAR attempt in the anamnesis, bluish red color skin changes suggestive of venous hypertension, scrotal edema and priapism in the body such as phlegmasia cerulea dolens starting from the upper quadrant of the abdomen and extending to the feet, and thrill removal in the left lower quadrant in the abdominal examination enabled the diagnosis before imaging. The change in skin color seen extending from the upper quadrant of the abdomen to the feet was considered to be a distinctive finding in terms of ACF. The existing skin findings were remarkable, when the patient was first seen, and this could not be explained by any rash and/or allergic reaction.

In conclusion, good mapping of preoperative anatomical suitability in EVAR procedures can 
prevent the occurrence of many complications. Taking a thrill in the abdominal examination and the presence of skin changes reminiscent of phlegmasia cerulea dolens can suggest the preliminary diagnosis of ACF. Endovascular methods are fast and life-saving treatment of choice in the treatment of Type 3 endoleak and ACF in appropriate anatomical conditions.

\section{Declaration of conflicting interests}

The authors declared no conflicts of interest with respect to the authorship and/or publication of this article.

\section{Funding}

The authors received no financial support for the research and/or authorship of this article.

\section{REFERENCES}

1. Schmidt R, Bruns C, Walter M, Erasmi H. Aorto-caval fistula--an uncommon complication of infrarenal aortic aneurysms. Thorac Cardiovasc Surg 1994;42:208-11.

2. Abbadi AC, Deldime P, Van Espen D, Simon M, Rosoux P. The spontaneous aortocaval fistula: a complication of the abdominal aortic aneurysm. Case report and review of the literature. J Cardiovasc Surg (Torino) 1998;39:433-6.

3. Alexander JJ, Imbembo AL. Aorta-vena cava fistula. Surgery 1989;105:1-12.

4. Özdemir AC, Gemalmaz H, Yilmaz F. Aortoenteric fistulas: A case report and current status. Cardiovasc Surg Int 2020;7:193-8.

5. White GH, May J, Waugh RC, Chaufour X, Yu W. Type III and type IV endoleak: toward a complete definition of blood flow in the sac after endoluminal AAA repair. J Endovasc Surg 1998;5:305-9.

6. Juszkat R, Pukacki F, Zarzecka A, Kulesza J, Majewski W. Endovascular treatment of ruptured abdominal aneurysm into the inferior vena cava in patient after stent graft placement. Cardiovasc Intervent Radiol 2009;32:776-80.

7. Shah TR, Parikh P, Borkon M, Mocharla R, Lonier J, Rosenzweig BP, et al. Endovascular repair of contained abdominal aortic aneurysm rupture with aortocaval fistula presenting with high-output heart failure. Vasc Endovascular Surg 2013;47:51-6. 